nothing in the shape of an annuity, whilst ander Table No. 3 he will receive £24. 18s. 8d. per annum for the remainder of his life. In this illastration I have disregarded the provision of the Act, that no person can assure an annuity of more than $\mathfrak{E} 30$, and also any rule which may exist as to insuring fractions of a pond, as these can have no bearing on the question before us; but it may, perhaps, be as well to point out that, as in the Government tables, the preminms for deferred annuities are, of course, payable at the beginning, whilst in the formula which $I$ bave given they are payable at the end of the year, the assurance under Table No. 3 must be made at the age of $x+1$ for $n-1$ years.

In conclusion, allow me to draw your attention to the table for deferred annuities (money not retarnable), which has this week been laid before Parliament. In it are given tables of immediate annuities and tables of deferred annuities; with these materials, the valnes of annuities for terms of years are immediately obtained, with the following results:-

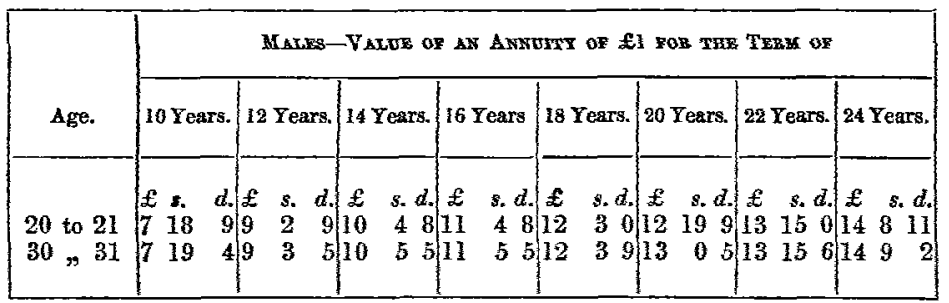

in all of whieh cases it will be seen that the value of a life at 31 is greater than that of a life at 21 ; and similarly it may be shown that the value of an annity for 10 years is precisely the same at the ages of 21 and 39 .

I hope, on a future occasion, to be allowed to prove that the annnal premiums payable under the "money returnable" scale are open to the same objections, although not to the same degree, as those which I have urged against the single premiums under a like condition.

I am, dear Sir,

Yours truly,
London, 25th February, 1865.
J. W. STEPHENBON.

\title{
MR. SPRAGUE'S LETTER IN THE LAST NUMBER OF THE JOURNAL.
}

To the Editor of the Assurance Magazine.

Sik,-It was my intention to have asked yon to be good enough to insert a reply, which I have written at some length, to the letter of Mr. Sprague which appeared in the last Number of the Magazine. But some of my friends, on whose judgment I piace great reliance, who have seen the manascript, arge me to withdraw it, on the ground that the affairs of particular Societies ought not, under any circumstances, to be discussed in the Journal of the Institute. For this reason, and for this reason only, I abstain from entering into further controversy on the subject.

I have the honour to be,

$$
\begin{aligned}
& \text { Sir, } \\
& \text { Your obedient servant, }
\end{aligned}
$$

10 th March, 1865.

ARTHUR H. BAILEY. 